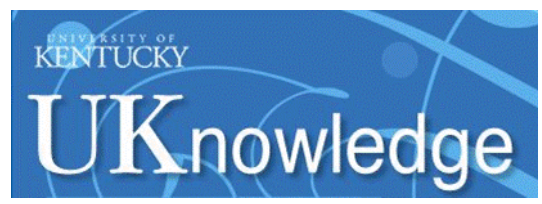

University of Kentucky

UKnowledge

\title{
The Effects of Stimulant Medication on Free Recall of Story Events among Children with ADHD
}

\author{
Ursula L. Bailey \\ University of Kentucky, ulbail2@uky.edu \\ Karen J. Derefinko \\ University of Kentucky, karen.derefinko@uky.edu \\ Richard Milich \\ University of Kentucky, richard.milich@uky.edu \\ Elizabeth P. Lorch \\ University of Kentucky, elorch@uky.edu \\ Amanda Metze \\ University of Kentucky, amanda.metze@uky.edu
}

Follow this and additional works at: https://uknowledge.uky.edu/psychology_facpub

Part of the Child Psychology Commons

Right click to open a feedback form in a new tab to let us know how this document benefits you.

\section{Repository Citation}

Bailey, Ursula L.; Derefinko, Karen J.; Milich, Richard; Lorch, Elizabeth P.; and Metze, Amanda, "The Effects of Stimulant Medication on Free Recall of Story Events among Children with ADHD" (2011). Psychology Faculty Publications. 4.

https://uknowledge.uky.edu/psychology_facpub/4

This Article is brought to you for free and open access by the Psychology at UKnowledge. It has been accepted for inclusion in Psychology Faculty Publications by an authorized administrator of UKnowledge. For more information, please contact UKnowledge@lsv.uky.edu. 
The Effects of Stimulant Medication on Free Recall of Story Events among Children with ADHD

Digital Object Identifier (DOI)

10.1007/s10862-011-9249-2 
STIMULANT MEDICATION AND RECALL

The Effects of Stimulant Medication on Free Recall of Story Events among Children with ADHD 
STIMULANT MEDICATION AND RECALL

\begin{abstract}
This study investigated group differences in the recalls of stories by children with attention-deficit/hyperactivity disorder (ADHD) and comparison peers. Further, the study examined whether stimulant medication improved the story recall of children with ADHD relative to a placebo condition. Children were asked to recall both televised and audio taped stories. Free recall protocols were assessed for what information was recalled as a function of story structure features (i.e. status on or off the causal chain and event importance) and were rated for overall coherence. Relative to comparison peers, children with ADHD showed less influence of story structure features on recall, and produced less coherent recall of the audio taped stories. Medication had only limited effects on the story recall of children with ADHD. Specifically, medication did not increase these children's sensitivity to events central to the stories and had no effect on the coherence of children's recalls. The implications of the results for guiding future academic interventions are discussed.
\end{abstract}

Key words: ADHD, medication, story recall, coherence 
STIMULANT MEDICATION AND RECALL

The Effects of Stimulant Medication on the Free Recall of Story Events among Children with ADHD

Research on the treatment of childhood with ADHD, although extensive, is characterized by a puzzling set of findings. Stimulant medication, the most common treatment for the disorder, has been shown to be effective in reducing classroom disruptions and increasing on-task behavior and short-term academic productivity (DuPaul \& Eckert, 1997; Loe \& Feldman, 2007). However, evidence is lacking to document that these short-term improvements have a positive impact on long-term academic performance (MTA Cooperative Group, 2007). One explanation for this lack of long-term improvement is that stimulant medication may not have an impact on higher order cognitive functions that are necessary for academic success. Story comprehension abilities represent such higher order cognitive processes that play a crucial role in academic achievement.

The skills necessary for effective story comprehension include the ability to evaluate, encode, and integrate information (Lorch, Berthiaume, Milich, \& van den Broek, 2007). Studying comprehension allows an examination of how children select and encode important story events, integrate relevant background information with story events to build a coherent representation, and use the story representation to guide retrieval and recall of the story (Trabasso, Secco, \& van den Broek, 1984). There is evidence that early, prereading narrative comprehension abilities predict later reading achievement, beyond the contributions of traditional indicators of literacy, such as word identification and vocabulary (Kendeou et al., 2005). Similarly, Feagans and Applebaum (1986) reported that stronger first grade narrative skills predicted fewer academic problems three years later, even when controlling for syntactic and semantic skills. 
STIMULANT MEDICATION AND RECALL

\section{Story Comprehension and Recall among Children with ADHD}

Given the documented link between story comprehension abilities and academic achievement, it is important to examine these abilities among children with ADHD. Research on story comprehension and recall has revealed consistent deficits among children with ADHD. These children have difficulty using the goal structure of stories to guide story narrations (Flory et al., 2006; Renz et al., 2003) and have problems making causal connections between story events (Bailey, Lorch, Milich, \& Charnigo, 2009; Lorch, Eastham et al., 2004). When children with ADHD are asked to produce free recalls of stories, a consistent pattern of deficits is obtained. Specifically, these children include less information in their recalls than do their comparison peers (Lorch, Diener, et al., 1999; Lorch, Milich, Flake, Ohlendorf, \& Little, 2010), are less guided by causal structure within stories (Lorch, Diener, et al., 1999; Lorch, Sanchez et al., 1999), and are less influenced by thematic importance (Flake, Lorch, \& Milich, 2007; Lorch, et al., 2010). In addition to deficits in the specific information recalled by children with ADHD, their recalls are judged to be less coherent than those of comparison peers (Lorch et al., 2010). Taken together, these findings provide compelling evidence that children with ADHD demonstrate deficits in story comprehension and recall.

\section{Story Comprehension and Stimulant Medication}

The evidence for deficits in story comprehension and recall among children with ADHD comes from studies in which the purpose was to examine any deficits independent of medication. Because of this, children were required to be free of stimulant medication for at least 24 hours prior to participation in each of the aforementioned studies. Therefore, it is unknown what impact stimulant medication may have on story comprehension and recall among children with ADHD. Stimulant medication is the most common treatment for children with ADHD (Barkley, 
STIMULANT MEDICATION AND RECALL

2006), and has been demonstrated to be effective for improving on-task behavior in the classroom and increasing short-term academic productivity (DuPaul \& Eckert, 1997; Loe \& Feldman, 2007). However, stimulant medication does not appear to improve academic performance over time (Fabiano \& Pelham, 2002; Fischer, Barkley, Smallish, \& Fletcher, 2002; Barkley, 2006), even in large-scale treatment studies (MTA Cooperative Group, 2007).

To date, only two studies have examined the effects of stimulant medication on story comprehension. Francis, Fine, \& Tannock (2001) asked children to recall a story that they had heard while looking at a corresponding wordless picture book. Children completed this task both on and off stimulant medication. Although children showed some improvement in mentioning story characters' internal responses and attempts when on medication, stimulants did not improve story recall length or accuracy of responses to comprehension questions (Francis et al., 2001). Thus, this study suggests that stimulant medication may prime children with ADHD to perform short-term cognitive tasks by helping them focus and attend, but it does not appear to improve higher-order story comprehension abilities.

In a second study designed to examine story comprehension and stimulant medication, Derefinko, Bailey, Milich, Lorch, and Riley (2009) asked children to narrate two wordless picture books, once on their typical stimulant medication dose and once on placebo. Assessment of children's comprehension was based on story grammar theory, which characterizes story structure in terms of goal-attempt- outcome sequences (Trabasso, Stein, Rodkin, Munger, \& Baughn, 1992). Consistent with previous research (Flory et al., 2006; Renz et al., 2003), comparison children more frequently included the positive outcome of the story, completion of the overall goal, and specific attempts linked to the goal than did the children with ADHD on placebo. When on medication as compared to placebo, children with ADHD included more 
STIMULANT MEDICATION AND RECALL

clauses in their narrations, but medication did not significantly affect children's inclusion of goal-based story events. Taken together, the findings of Derefinko et al. (2009) and Francis et al. (2001) reveal little effects of medication on reducing story comprehension deficits of children with ADHD.

\section{The Current Study}

The current study investigates group differences in the free recall of stories by children with ADHD and comparison children, and explores the potential impact of stimulant medication on story recall in children with ADHD. Children completed free recall tasks with two types of story materials, one a televised situation comedy and one a brief audiotaped fable. Both recall tasks were completed twice, using two different versions of each type of story. Children with ADHD completed one of each task while on medication and one of each task while on placebo, whereas the comparison children did all tasks without medication or placebo.

The current study represents an extension of the study conducted by Derefinko et al. (2009), which examined the effects of stimulant medication on online story narration of children with ADHD. The use of a free-recall methodology, in contrast to online story narration, requires children to view and/or hear an entire story before attempting to do a complete recall of the story. This places greater demands on memory and organizational processes than does online story narration, for which children can proceed through the picture book at their own pace and can use pictures as cues to story events. As such, one focus of the present analyses is on the extent to which features of story structure differentially predict recall in comparison children and children with ADHD. Specifically, we examine whether the two groups differ in the extent to which they show better recall as story events increase in thematic importance (e.g., Flake et al., 2007) and when events are part of the causal chain that ties events together from beginning to end of the 
STIMULANT MEDICATION AND RECALL

story (e.g., Lorch, Diener et al., 1999).

A second focus of the current investigation is on the coherence of children's free recalls. In order for children to succeed in story processing tasks that are relevant to academic performance (e.g., writing book reports, summarizing stories), they must be able to integrate these components into a coherent whole (van den Broek, 1997). Thus, groups were compared on the coherence of children's recalls as rated by trained coders.

Children with ADHD have shown less sensitivity to thematic importance and causal chain status (Flake et al., 2007; Lorch, Diener et al., 1999). There also is some evidence that their recalls are less coherent than those of comparison peers (Lorch et al., 2010). However, nothing is known about the effects of stimulant medication on children's sensitivity to story structure variables or on the coherence of children's recalls. The major purpose of the current study is to investigate whether medication improves these critical aspects of children's story recall.

\section{Method}

\section{Participants}

A sample of 42 children (17 children with ADHD/combined type and 25 comparison children) participated in this study. The children, between the ages of 9.0 and 13.8 years ( $M$ age $=11.6$ years, $S D=1.16$ ), were the same participants included in the study by Derefinko et al., (2009). Thirty-four of the children were Caucasian, 3 identified themselves as biracial, 5 identified themselves as African American, and 1 identified as Latina/o. In the ADHD group, 14 $(82.4 \%)$ of the children were male, and in the comparison group, $20(80.0 \%)$ were male. The children with ADHD were recruited from the Hyperactive Children's Clinic in the School of Medicine at the University of Kentucky. The children were carefully selected to fulfill the DSM$I V$ criteria for ADHD/combined subtype and to be free of confounding factors (i.e., low IQ, 
STIMULANT MEDICATION AND RECALL

neurological problems). Diagnoses were based on a convergence of evidence from multiple measures and informants. Children who exhibited only attentional problems (i.e., the inattentive subtype) were not contacted for participation.

Children were first required to have received the appropriate DSM-IV (American Psychiatric Association, 1994) ADHD/Combined Type diagnosis based on a comprehensive psychiatric clinic evaluation at the Hyperactive Children's Clinic. This evaluation utilizes multiple assessment procedures designed to identify psychiatric and neurological factors that may influence or better account for ADHD symptoms, such as mood disorders, developmental disorders, epilepsy or neurological disorders, or mental retardation. In addition, the medical charts of all the children were reviewed in detail to gather specific information about ADHD diagnoses and medical history, including reason for clinic referral, age at onset of symptoms, classroom behavior via teacher ratings, evidence of impairment, parent ratings of behavior, IQ, medical history, and comorbid diagnoses. Children were not eligible for the study if their medical charts provided evidence of IQ scores lower than 80, presence of sensory impairments, diagnoses of epilepsy or other neurological disorders, or prescribed medication that could not be temporarily discontinued during study participation. Finally, children with ADHD were required to be prescribed a stimulant medication at the time of participation in the study. Children who were not prescribed stimulant medication were not eligible for the study.

If the above criteria were met, then a parent of the child with ADHD was contacted and invited to participate in the study. During the first testing session, a semi-structured interview, similar to the P-ChIPS (Weller, Weller, Fristad, Rooney, \& Schecter, 2000), but only consisting of verbatim $D S M-I V$ criteria for ADHD and ODD, was conducted with the parent to confirm the child's diagnostic status. This interview also provided a common measure of ADHD symptoms 
STIMULANT MEDICATION AND RECALL

for all children in the study, because the assessment measures used to make the initial clinic diagnosis varied. The interviews were conducted by trained psychology graduate students. In the interview, the parent was asked whether each diagnostic criterion was true of his/her child, and, if so, the parent was asked to give behavioral examples. If a behavior was characteristic of the child, the parent was additionally asked whether that behavior seemed inappropriate for the child's age and whether it impaired the child's functioning academically and/or socially. A diagnostic criterion was considered to be endorsed only if the parent indicated the behavior was age-inappropriate and impairing. This interview procedure has been used successfully in previous studies, with interrater reliabilities for the number of ADHD symptoms endorsed by the parent above $95 \%$ (Lorch, Sanchez et al. 1999). In addition to the information from the structured psychiatric interview, parents completed the Conners (1997) Parent Rating Scales (CPRS-R:S). To be placed in the ADHD group, children must have met criteria for this diagnosis on the structured interview, and have T scores above 60 on the Conners Hyperactivity scale and the ADHD Index.

The comparison group of children without ADHD was recruited through newspaper advertisements, posted advertisements in the community, and by word-of-mouth. They were screened during a recruitment phone call in which the parents were asked if their child had ever been referred for any behavioral or learning problems. The comparison children were not required to be symptom free, but had to have three or fewer symptoms in a diagnostic category. These children were significantly less symptomatic than the children with ADHD in terms of the DSM-IV criteria for inattentive, hyperactive, and oppositional symptoms, and moreover did not meet diagnostic criteria for any subtype of ADHD. In addition, the children in the comparison group had T scores below 60 on all of the Conners rating scales. As indicated in Table 1, the 
STIMULANT MEDICATION AND RECALL

diagnostic interview and Conners rating scale data successfully differentiated between the comparison children and the ADHD group.

Among the seventeen children with ADHD, it was required that they were being treated with psychostimulant medication. Children with ADHD were being prescribed one of the following: methylphenidate hydrochloride ( $n=11$; dosage ranged from 18 to $54 \mathrm{mg}$ ), amphetamine/dextroamphetamine ( $n=3$; dosage ranged from 15 to $30 \mathrm{mg}$ ), methylphenidate transdermal system $(n=2$; dosage $=30 \mathrm{mg})$, and dexmethylphenidate hydrochloride $(n=1$; dosage $=30 \mathrm{mg}$ ). Participants who were receiving other medications that could not be easily withdrawn for testing (e.g., chlonidine) were not eligible for the study. All children received two small toys and \$20.00 for their participation in each session. Groups were not significantly different on the basis of age, gender, parental education, or racial composition.

\section{Procedure}

Children in both the ADHD and comparison groups attended two individual testing sessions that occurred at least one week apart. Children viewed one television program during each session and the order of the programs was counterbalanced. Similarly, the children listened to one fable in each session, and the order of the fables was counterbalanced. For the children with ADHD, their medication/placebo sessions were randomized prior to participation. Upon arrival, children and parents were greeted by a trained graduate student and written consent was obtained from the parent and verbal assent was obtained from the child. If the child was 13 , written assent was obtained in addition to the written consent of the parent was obtained.

Parents of children with ADHD completed a brief intake interview regarding the child's medication and dosage. On medication days, children with ADHD were required to have taken their usual dosage of stimulant medication one hour prior to testing. Because parents had to 
STIMULANT MEDICATION AND RECALL

ensure administration of medication at home, they were not blind to medication status. Although children were aware that they were being administered their usual medication on medication days, they were unaware that they would be receiving placebo on those days or what the pill contained. On placebo days, children with ADHD were required to have been off their usual medication for 24 hours prior to testing. The trained graduate student confirmed the child's medication-free status and presented a small blue and white placebo to the parent to administer to the child. Both the parent and the child were given the following instructions: "This is something we are testing in our research. We know it is perfectly safe." Parents instructed their child to swallow the pill with water provided. For children who were unable to swallow pills $(N=2)$, the placebo capsule was opened and its contents stirred into a cup of water for the child to drink. Due to the randomization of medication and placebo days, all children were debriefed about the placebo upon completion of the second and final session of the study. Parents of comparison children were also briefly interviewed about any medication that their child may have taken to ensure that medications that would impact performance had been not administered.

After the intake interview, all children were introduced to a trained undergraduate research assistant and were allowed to choose a small toy from a box. Research assistants who tested children were blind to diagnostic group status and medication status. The research assistant escorted the child to a private room where they began the tasks. While a child was being tested in a separate room, parents completed a DSM-IV interview and Conners (1997) Parent Rating Scale with the trained graduate student.

During each testing session, children viewed one of two episodes of the situation comedy, Growing Pains. These episodes have been used extensively in studies of story comprehension among children with ADHD (e.g., Lorch, Eastham et al., 2004; Lorch et al., 
STIMULANT MEDICATION AND RECALL

2000). There were toys available for the child to play with if they wished while they watched the program. They were given the following instructions: "There will be a television show for you to watch in a few minutes. When I come back I'm going to ask you some questions about what you saw. There are toys here and you can play with them too while you watch. Remember, when I come back, I'm going to ask you questions about the show you just saw." At the conclusion of the show, the research assistant returned to the room and asked the child to tell everything they remembered about the story from beginning to end. There was also a picture card with the show characters for the child in the event that they could not remember names.

During the same session, children were played one of two audiotaped fables, The Father, His Son, and Their Donkey or A Test of Strength. The fables have been used in previous studies of recall in children with ADHD (e.g., Lorch, Diener et al.,1999; Lorch, O’Neil et al., 2004). After the children heard the fable, they were immediately asked to recall everything that they remembered about the fable from beginning to end. Each session was audiotaped and videotaped for transcription and coding.

\section{Materials}

Each commercial-free episode of Growing Pains lasted 23-minutes. The plots involved families, with specific focus on the children in the family. These episodes were chosen because content was age appropriate and appealing to children. Each episode was parsed into idea units of meaning; each unit represented a single idea or event. Causal network representations of the stories were derived (Trabasso \& van den Broek, 1985), with each representation yielding a causal chain of events that carried the story from beginning to end. Each story event was coded as to whether it was on or off the causal chain.

Importance ratings were collected for each story event within the two Growing Pains 
STIMULANT MEDICATION AND RECALL

episodes (see Lorch, O’Neil et al., 2004). College students rated each event (1= not important to the overall meaning of the story; $7=$ extremely important to the overall meaning of the story) after viewing the program. For each story event, a mean importance rating was calculated and those means were separated into quartiles for each story. The bottom and top quartiles were used in the analysis to indicate the least and most important information, respectively, with the middle $50 \%$ of events considered of medium importance. This procedure ensured standardization of the importance ratings for each Growing Pains episode.

Each fable was approximately 4 minutes in length. Each had been divided into discrete story events (The Father, His Son, and Their Donkey=63, A Test of Strength=62). The thematic importance ratings had been previously determined by adult raters and divided into 4 levels of importance (Brown, Day, \& Jones et al., 1983). Causal network analyses produced a causal chain for each story (Trabasso \& Sperry, 1985). The two stories were similar in terms of difficulty, length, number of story events, and number of events at each level of importance.

\section{Coding}

Children's free recall protocols for both types of stories were transcribed verbatim by a coder blind to group status and study hypotheses. Transcriptions were based on audiotaped recalls unless portions were inaudible in which case videotape recordings were consulted. Transcriptions were checked for accuracy and corrected when necessary. The recall protocols were parsed into individual events and compared to the story events obtained from the parsing of the episodes or fables. A score of 0/1 (not recalled/recalled) was assigned for each story event. The child was not required to recall the event verbatim, just to capture the gist of the event. To estimate interrater reliability for coding, a subset of the protocols was scored twice, producing a kappa value of 0.93 . 
STIMULANT MEDICATION AND RECALL

Children's recalls of both types of stories were judged for overall coherence by adult raters, on a scale of $1-4(1=$ not at all coherent; $4=$ very coherent $)$. The criteria for the four levels were as follows: "1" reflected poor transitions from one idea to the next, poor connections while talking about the same idea, poor overall flow (choppy), significant difficulty explaining the sequence of events, and little or no storyline maintained; "2" signified some appropriate transitions to new ideas and connections within an idea, but difficulty explaining the sequence of events, some parts of the storyline maintained but little substance; "3" reflected appropriate transitions to new ideas and connections within an idea with good overall flow, only minor problems with transitions or connections, explains sequence of event clearly but with some ambiguities; and '4' signified appropriate transitions to new ideas and connections within an idea with good overall flow, explains the sequence of events clearly with no or very few ambiguities. The interrater reliability for scoring coherence was .71 for fables and .79 for Growing Pains.

\section{Results}

For each of the two story comprehension tasks, overall recall was assessed as well as recall as a function of story structure variables (e.g., events on or off the causal chain, event importance). In addition, for both tasks coders rated the global coherence of each story recalled. The first set of analyses compared diagnostic group differences of children on the two story comprehension tasks, in order to examine whether story structure features are better predictors of recall for comparison children than for children with ADHD. For these analyses, the comparison children's performance was averaged across the two sessions and was tested against that of children with ADHD on placebo. The second set of analyses included only the children with ADHD and evaluated whether the pattern of results differed when children were on placebo versus on stimulant medication. 
STIMULANT MEDICATION AND RECALL

\section{Group Differences in Story Recall}

Growing Pains. Group comparisons on the story recall variables are presented in Table

2. Comparison children and children with ADHD did not differ significantly in the total number of events recalled, $F(1,40)=1.73, p>.10$. For both groups of children, recall increased as the importance level of the events increased, $F(2,80)=185.16, p<.001, d=3.11$. Consistent with previous findings (Flake et al., 2007; Lorch et al., 2010), there was a significant interaction of diagnostic group and importance level, $F(2,80)=3.28, p<.05, d=.41$, such that the linear increase in comparison children's recall as a function of thematic importance was steeper than that of children with ADHD, $F(1,40)=4.17, p<.05, d=.63$. Similarly, both groups of children recalled more events that were part of the causal chain than events off the causal chain, $F(1,40)$ $=231.23, p<.001, d=4.72$. Again consistent with previous findings (Lorch et al., 1999), the effect of causal chain status on recall was stronger for comparison children than for children with ADHD, $F(1,40)=4.13, p<.05, d=.63$. The two groups of children did not differ in the global ratings of coherence of the recalled story, $t(39)<1$.

Fables. Group comparisons on the story recall variables are presented in Table 2. Comparison children and children with ADHD did not differ significantly in the total number of story events recalled, $F(1,40)<1$. For both groups of children, recall increased as the importance level of the events increased, $F(3,120)=169.17, p<.001, d=2.41$. As was the case for the Growing Pains episodes, there was a significant interaction of diagnostic group and importance level, $F(3,120)=4.07, p<.05, d=.35$. However, the source of the interaction was a significant cubic component, $F(1,40)=12.95, p<.001, d=1.13$, such that comparison children's recall increased more steeply between the two intermediate levels of importance than did that of children with ADHD. In contrast to previous findings, the two groups of children did 
STIMULANT MEDICATION AND RECALL

not differ in their recall of the most important events. Both groups of children recalled more events that were part of the causal chain than events off this causal chain, $F(1,40)=173.22, p<$ $.001, d=4.09$, and there was no group difference in the effect of causal chain status on recall, $F(1,40)<1$. Despite the similarity in the pattern of events recalled from the fables, comparison children's recalls were rated significantly more coherent than those of the children with ADHD, $t(40)=2.43, p<.05, d=1.03$. These results are consistent with the findings from Lorch et al. (2010) and Freer, Lorch, Milich, and Haydon (2010).

\section{Medication Effects on Story Recall}

Growing Pains. The effects of stimulant medication on the story recall variables for children with ADHD are presented in Table 3. Consistent with previous research (Derefinko et al., 2009), stimulant medication increased the overall number of story events recalled, $F(1,16)=$ $4.82, p<.05, d=1.09$. As expected from theory and previous research, recall increased as the importance of story events increased, $F(2,32)=82.16, p<.001, d=3.21$, and recall was higher for events that were part of the causal chain than for events off the causal chain, $F(1,16)=$ 130.78, $p<001, d=5.37$. However, stimulant medication did not interact significantly with either importance level, $F(2,32)=1.89, p>.10$, or causal chain status, $F(1,16)=1.12, p>.10$, nor did it influence ratings of coherence, $t(15)=0$. This pattern of findings suggests that although medication may increase productivity in general, it may not be sufficient to improve the pattern of recall of story events.

Fables. The effects of stimulant medication on story recall are presented in Table 3. In contrast to the results for Growing Pains, stimulant medication did not increase overall recall of story events, $F(1,16)<1$. Again, as expected from theory and research, children remembered more events as importance level increased, $F(1,16)=350.59, p<.001, d=9.9$, and more events 
STIMULANT MEDICATION AND RECALL

that were part of the causal chain than events off the causal chain, $F(1,16)=102.55, p<001, d$ $=5.03$. Stimulant medication did not interact significantly with importance level, $F(2,32)=$ $1.92, p>.10$, but did interact significantly with causal chain status, $F(1,16)=4.22, p=.057, d=$ 1.02. Children with ADHD remembered more events off the causal chain on medication than on placebo, but recall of events on the causal chain was unaffected by stimulant medication. Finally, stimulant medication did not affect the ratings of global coherence, $t(16)=1.46, p>.10$. Thus, as with the Growing Pains episodes, stimulant medication did not help children with ADHD increase recall of events central to the fables.

\section{Discussion}

The current study investigated group differences in the pattern and coherence of the free recall of stories by children with ADHD and comparison children, and examined the impact of stimulant medication on story recall in children with ADHD. The results of the current study point to deficits among children with ADHD similar to those identified in previous studies. Specifically, children with ADHD, as compared to their peers, showed less sensitivity to the thematic importance and causal chain status of story events in recalling the Growing Pains episodes. Further, on the fables task, the recalls of children with ADHD were rated significantly less coherent than those of comparison children. Although not all group differences were significant, those reported are consistent with previous studies (Lorch, Diener, et al., 1999; Flake et al., 2007; Lorch et al., 2010).

The major purpose of the current study was to determine if stimulant medication would improve the pattern and coherence of recall among children with ADHD. Consistent with the findings of Derefinko et al. (2009), stimulant medication had only limited effects on the recall performance of children with ADHD. Although children produced more story events from the 
STIMULANT MEDICATION AND RECALL

Growing Pains episodes and more events off the causal chain from the fables while on medication as compared to placebo, medication was not effective in selectively aiding recall of information central to the stories. Further, medication had no effect on the rated coherence of the recalls of children with ADHD, even when a group difference was observed for the fables. Although a group difference was not found for the Growing Pains episodes, other studies are consistent with the results for fables, documenting group differences in coherence of recalls (Lorch et al., 2010) and in stories created by children (Freer et al., 2010).

The failure to obtain medication effects on the coherence ratings is especially noteworthy, given the importance of the ability to produce coherent narratives. Compared with an assessment of what story events are recalled, by definition the ratings of coherence incorporate an evaluative judgment of the quality of children's representations of the stories. As such, these coherence ratings may resemble an important component of teachers' evaluations of school assignments, including book reports, journal entries, and responses to writing prompts, especially as children grow older. Beyond academic performance, difficulties in formulating coherent narratives may impede conversations and social interactions (Leonard, Milich, \& Lorch, in press), in turn contributing to the social problems experienced by children with ADHD (Sibley, Evans, \& Serpell, 2010).

To better understand the absence of medication effects on coherence ratings, it may be helpful to consider what skills are needed to produce coherent narratives. Some of these skills are basic cognitive processes, such as the ability to sustain attention to a narrative and persist in completion of the recall task. It is reasonable to propose that medication would have a positive impact on these basic processes. Such an interpretation is consistent with past research demonstrating increases in academic productivity while children are on medication (DuPaul \& 
STIMULANT MEDICATION AND RECALL

Stoner, 2003), and with the findings from both Derefinko et al. (2009) and the present study that children with ADHD produced more story events in their narrations and in their recalls while on medication. However, producing a coherent narrative requires higher order skills that go beyond these basic processes. These include identifying important story events and keeping them active in working memory while processing new events (Zwaan, 1999); encoding these events and their connections to construct a story representation (Trabasso et al., 1984); and using the story representation to plan and retrieve a recall that integrates story events (Trabasso \& Stein, 1997). In addition, coherence is likely to be enhanced by the ability to use world knowledge to make plausible inferences about how events are connected (Trabasso \& Magliano, 1999) and to take the perspective of the listener in maintaining clear referents throughout the recall (van den Broek, 1989).

All of these higher order skills needed to produce a coherent narrative are areas in which children with ADHD have demonstrated difficulties (Barkley, 2006; Lorch et al., 2007). There is little evidence that medication enhances these higher order skills. Nor is there good reason to predict that medication should do so, given that such skills develop over time (van den Broek, 1997). During the elementary school years comparison children show evidence of learning skills necessary to connect story events whereas children with ADHD fall behind their peers in the development of such skills (Bailey et al., 2009). If these children have not learned how to produce a coherent narrative, it is not reasonable to expect medication to improve their performance.

If medication is not sufficient to help children with ADHD acquire the skills necessary to produce coherent narratives, what type of intervention would be needed to achieve this goal? The other major validated treatment for ADHD is behavior modification (Pelham \& Fabiano, 2008). 
STIMULANT MEDICATION AND RECALL

Similar to medication, behavior modification has been shown to increase time on task and academic productivity (DuPaul \& Stoner, 2003). However, also similar to medication, there is no reason to assume that behavior modification by itself would elicit the skills necessary to connect story events into coherent representations. Instead, interventions need to be developed that target these higher order skills (Berthiaume, 2006; Lorch et al., 2007). The use of medication and/or behavior modification certainly could facilitate this training, but the training needs to focus on addressing the specific deficits in story comprehension observed among children with ADHD.

An examination of the education literature suggests that there are techniques available that are promising for developing story comprehension skills among children with ADHD. For example, if these children have difficulty making connections between story events, teaching children to use a graphic organizer to identify connections between events may benefit the construction of a coherent story representation (Duffy et al., 1987). Similarly, if these children have difficulty identifying characters' goals and the actions motivated by goals, teachers can use a think-aloud procedure (Trabasso \& Magliano, 1996) to model how to recognize a character's goal and look for how these goals lead to actions and outcomes in the story. The development of such interventions may help prevent children with ADHD from continuing to fall behind their peers as the complexity of academic tasks increases (Bailey et al., 2009).

\section{Limitations}

Several limitations of the current study need to be acknowledged. Some of these relate to the medication protocol. The common procedure in studies of this type is to use a standard medication (e.g., methylphenidate) and dosage (e.g., .3mg/kg). Instead, our emphasis in the current study was to conduct a more naturalistic investigation of the effects of stimulant medication on story recall. As such, using individually prescribed dosages enabled examination 
STIMULANT MEDICATION AND RECALL

of how the stimulant medication typically experienced by the children during the school day affects performance on these academically-related recall tasks. It also needs to be noted that we did not use the standard placebo procedure, in which children do not know when they are on their regular medication. However, studies using placebo-controlled designs with children do not demonstrate significant placebo effects (Pelham, Hoza, Kipp, Gnagy, \& Trane, 1997).

Another limitation is that the current study replicated some but not all previous findings of group differences in story recall. Generally, the pattern of findings for recall of the Growing Pains episodes replicated that of previous studies, but the pattern for fables was somewhat different. Interestingly, however, previous findings of group differences in the coherence of children's recalls (Freer et al., 2010; Lorch et al., 2010) were replicated for the fables task. Taken together with past findings, the overall pattern of results in the current study points to reliable deficits in recall of central story information by children with ADHD and in the coherence of these children's narrative constructions. The observed group differences allow for a meaningful examination of the effects of stimulant medication on the story recalls of children with ADHD.

The results of this study as well as the findings from Derefinko et al. (2009) and Francis et al. (2001) suggest that medication alone will not eliminate the story comprehension deficits of children with ADHD. Future research needs to focus on developing and evaluating educational interventions designed to target specific story comprehension difficulties experienced by children with ADHD. Research then can examine the ways in which medication may facilitate implementation of these educational interventions, with the eventual goal of improving the academic achievement of children with ADHD.

Acknowledgments: This research was supported by the National Institute of Mental Health Grant MH47386 and the National Institute on Drug Abuse grant DA 05312. 
STIMULANT MEDICATION AND RECALL

\section{References}

Ackerman, B.P., Silver, D.; \& Glickman, I. (1990). Concept availability in the causal inferences by children and adults. Child Development, 61, 230-246.

American Psychiatric Association. (1994). Diagnostic and statistical manual of mental disorders $\left(4^{\text {th }}\right.$ ed.). Washington, DC: Author.

Bailey, U.L., Lorch, E.P., Milich, R., \& Charnigo, R. (2009). Developmental changes in attention and comprehension among children with attention deficit hyperactivity disorder. Child Development, 80, 1842-1855.

Barkley, R.A. (2006). Attention-deficit hyperactivity disorder: A handbook for diagnosis and treatment ( $3^{\text {rd }}$ ed.). New York: The Guilford Press.

Berthiaume, K.S. (2006). Story comprehension and academic deficits in children with attentiondeficit hyperactivity disorder: What is the connection? School Psychology Review, 35, 309-323.

Brown, A.L., Day, J.D., \& Jones, R.S. (1983). The development of plans for summarizing text. Child Development, 54, 968-979.

Conners, C.K. (1997). Conners' parent rating scales revised-short version. North Tonawanda, New York: Multi Health Systems.

Derefinko, K.J., Bailey, U.L., Milich, R., Lorch, E.P., \& Riley, E. (2009). The effects of stimulant medication on the online story narrations of children with ADHD. School Mental Health, 1, 171-182.

Duffy, G. G., Roehler, L. R., Sivan, E., Rackliffe, G., Book, C., Meloth, M. S., Vavrus, L. G., Wesselman, R., Putnam, J., \& Bassiri, D. (1987). Effects of explaining the reasoning associated with using reading strategies. Reading Research Quarterly, 22, 347-368. 
STIMULANT MEDICATION AND RECALL

DuPaul, G.J. \& Eckert, T.L. (1997). The effects of school-based interventions for attention deficit hyperactivity disorder: A meta analysis. School Psychology, 26, 5-27.

DuPaul, G.J. \& Stoner, G. (2003). ADHD in the schools: assessment and intervention strategies ( $2^{\text {nd }}$ ed.). New York: Guilford Press.

Fabiano G.A. \& Pelham, W.E. (2002). Measuring impairment in children with attention-deficit hyperactivity disorder. ADHD Report, 10, 6-10.

Feagans, L., \& Applebaum, M.I. (1986). Validation of language subtypes in learning disabled children. Journal of Educational Psychology, 78, 358-364.

Fischer, M., Barkley, R.A., Smallish, L., \& Fletcher, K. (2002). Young adult follow-up of hyperactive children: Self-reported psychiatric disorders, comorbidity, and the role of childhood conduct problems and teen CD. Journal of Abnormal Child Psychology, 30, 463-475.

Flake, R.A., Lorch, E.P., Milich, R. (2007). The effects of thematic importance on story recall among children with attention deficit hyperactivity disorder and comparison children. Journal of Abnormal Child Psychology, 35, 43-53.

Flory, K., Milich, R., Lorch, E.P., Hayden, A.N., Strange, C. \& Welsh, R. (2006). Online story comprehension among children with ADHD: Which core deficits are involved? Journal of Abnormal Child Psychology, 34, 853-865.

Francis, S., Fine, J. \& Tannock, R. (2001). Methylphenidate selectively improves storytelling in children with attention deficit hyperactivity disorder. Journal of Child and Adolescent Psychopharmacology, 11, 3, 217-228.

Freer, B.D., Lorch, E.P., Milich, R., \& Hayden, A. (2010). The stories they tell: Story production difficulties of children with ADHD. Manuscript under review. 
STIMULANT MEDICATION AND RECALL

Graesser, A.C. \& Clark, L.F. (1985). Structures and procedures of implicit knowledge. Norwood, NJ: Ablex.

Kendeou, P., Lynch, J.S., van den Broek, P., Espin, C., White, M., \& Kremer, K.E. (2005). Developing successful readers: building early comprehension skills through television and listening. Early Childhood Education Journal, 22, 91-98.

Leonard, M., Milich, R. \& Lorch, E.P. (In press). The role of pragmatic language use in mediating the relation between hyperactivity and inattention and social skills problems. Journal of Speech, Language, and Hearing Research.

Loe, I.M. \& Feldman, H.M. (2007). Academic and educational outcomes of children with ADHD. Journal of Pediatric Psychology, 36, 643-654.

Lorch, E.P., Berthiaume, K., Milich, R., \& van den Broek, P. (2007). Story comprehension impairments in children with attention-deficitt/hyperactivity disorder. In K. Cain \& J. Oakhill (Eds.), Cognitive bases of children's language comprehension difficulties (pp.128-156). New York: Guilford Press.

Lorch, E., Diener, M., Sanchez, R., Milich, R., Welsh, R., \& van den Broek, P. (1999). The effects of story structure on the recall of stories in children with attention deficit hyperactivity disorder. Journal of Educational Psychology, 91, 273-283.

Lorch, E., Eastham, D., Milich, R., Lemberger, C.C., Sanchez, R.P., Welsh, R., \& van den Broek, P. (2004). Difficulties in comprehending causal relations among children with ADHD: The role of cognitive engagement. Journal of Abnormal Psychology, 113, 56-63.

Lorch, E., Milich, R., Flake, R., Ohlendorf, J., \& Little, S. (2010). A developmental examination of story recall and coherence among children with ADHD. Journal of Abnormal Child Psychology, , 38, 291-301. 
STIMULANT MEDICATION AND RECALL

Lorch, E.P., Milich, R., Sanchez, R.P., van den Broek, P., Baer, S., Hooks, K., et al. (2000).

Comprehension of televised stories in boys with attention deficit/hyperactivity disorder and nonreferred boys. Journal of Abnormal Psychology, 109, 321-330.

Lorch, E., O'Neil, K., Berthiaume, K., Milich, R., Eastham, D., \& Brooks, T. (2004). Story comprehension and the impact of studying on recall in children with ADHD. Journal of Clinical Child and Adolescent Psychology, 33, 506- 515.

Lorch, E.P., Sanchez, R.P., van den Broek, P., Milich, R. Murphy, E.L., Lorch Jr., R.F., \& Welsh, R. (1999). The relation of story structure properties to recall of television stories in young children with attention-deficit hyperactivity disorder and non-referred peers. Journal of Abnormal Child Psychology, 27, 293-309.

Low, J. \& Durkin, K.(1998). Structure and causal connection in children's on-line television narratives: what develops? Cognitive Development, 13, 201-225.

Magliano, J.P., Trabasso, T., \& Graesser, A.C. (1999). Strategic processing during comprehension. Journal of Educational Psychology, 91, 615-629.

MTA Cooperative Group (2007). 14-Month randomized clinical trial of treatment strategies for attention deficit hyperactivity disorder. Archives of General Psychiatry, 56, 1073-1086.

Pelham, W.E. (2000). Stimulants. In A.E. Kazdin (Ed.), Encyclopedia of Psychology (Vol. 7, pp. 474-476). New York, NY: Oxford University Press.

Pelham, W.E., Jr., \& Fabiano, G.A. (2008). Evidence-based psychosocial treatments for attention-deficit/hyperactivity disorder. Journal of Clinical Child and Adolescent Psychology, 37, 184-214.

Pelham, W.E., Hoza, B. Kipp, H.L., Gnagy, E.M., \& Trane, S.T. (1997). Effects of methylphenidate and expectancy on ADHD children's performance, self-evaluations, 
STIMULANT MEDICATION AND RECALL

persistence, and attributions on a cognitive task. Experimental \& Clinical

Psychopharmacology, 5, 3-13.

Renz, K., Lorch, E.P., Milich, R., Lemberger, C., Bodner, A., \& Welsh, R. (2003). On-Line story representation in boys with attention deficit hyperactivity disorder. Journal of Abnormal Child Psychology, 31, 93-104.

Sibley, M.H., Evans, S.W., \& Serpell, Z.N. (2010). Social cognition and interpersonal impairment in young adolescents with ADHD. Journal of Psychopathology and Behavioral Assessment, 32, 193-202.

Storch, S., \& Whitehurst, G. (2002). Oral language and code-related precursors to reading: Evidence from a longitudinal structural model. Developmental Psychology, 38, 934-947.

Trabasso, T. \& Magliano, J. (1996). How do children understand what they read and what can we do to help them? In M. Graves, P. van den Broek, and B. Taylor (Eds.), The first R: Every child's right to read. New York: Teachers College Press.

Trabasso, T. \& Nickels, M. (1992). The development of goal plans of action in narration of a picture story. Discourse Processes, 15, 249-275.

Trabasso, T., Secco, T., \& van den Broek, P.W. (1984). Causal cohesion and story coherence. In H. Mandler, N.L. Stein, \& T. Trabasso (Eds.), Learning and comprehension of text (pp.83-111). Hillsdale, NJ: Erlbaum.

Trabasso, T \& Sperry, L.L. (1985). Causal relatedness and importance of story events. Journal of Memory and Language, 24, 595-611.

Trabasso, T. \& Stein, N.L. (1997). Narrating, representing, and remembering event sequences. In P.W. van den Broek, P.J. Baur, \& T. Bourgs (Eds.). Developmental spans in event comprehension and representation: Bridging fictional and actual events (pp. 237-270). 
STIMULANT MEDICATION AND RECALL

Mahwah, NJ: Erlbaum.

Trabasso, T., Stein, N.L., Rodkin, P.C., Munger, M.P., \& Baughn, C.R. (1992). Knowledge of goals and plans in the online narration of events. Cognitive Development, 7, 133-170.

Trabasso, T. \& van den Broek, P. (1985). Causal thinking and the representation of narrative events. Journal of Memory and Language, 24, 612-630.

Trabasso, T., Van den Broek, P., \& Suh, S. (1989). Logical necessity and transitivity of causal relations in stories. Discourse Processes, 12, 1-25.

van den Broek, P. (1989). Causal reasoning and inference-making in judging the importance of story statements. Child Development, 60, 286-297.

van den Broek, P. (1990). The causal inference maker: Towards a process model of inference generation in text comprehension. Comprehension processes in reading (pp. 423-445). Hillsdale, NJ England: Lawrence Erlbaum Associates, Inc.

van den Broek, P. (1997). Discovering the cement of the universe: The development of event comprehension from childhood to adulthood. . In P.W. van den Broek, P.J. Baur, \& T. Bourgs (Eds.). Developmental spans in event comprehension and representation: Bridging fictional and actual events (pp. 321-342). Mahwah, NJ: Erlbaum.

Weller, E.B., Weller, R.A., Roone, M.T., \& Fristad, M.A. (1999). Children's interview for psychiatric syndromes-parent version (P-ChIPS). Washington, D.C.: American Psychiatric Press.

Zwaan, R.A., (1999). Five dimensions of narrative comprehension: The event-indexing model. In S.R. Goldman, A.C. Graesser, \& P. van den Broek (Eds.), Narrative comprehension, causality, and coherence: Essays in honor of Tom Trabasso (93-110). Mahwah, NJ: Erlbaum. 
STIMULANT MEDICATION AND RECALL

Table 1

Descriptive and diagnostic information by group

$$
\text { Comp }(n=25) \quad \text { ADHD }(n=17)
$$

\begin{tabular}{lcccc} 
Variable & $M(S D)$ & $M(S D)$ & $F$ & $X^{2}$ \\
\hline Age (months) & $137.32(12.53)$ & $141.47(15.82)$ & .897 & .349 \\
Gender (\% male) & 80 & 82.4 & .04 & .849 \\
Race (\% white) & 80 & 82.3 & .04 & .849 \\
Mother's education (years) & $17.00(2.04)$ & $16.00(1.97)$ & 2.50 & .122 \\
Father's education (years) & $16.09(1.95)$ & $15.07(3.03)$ & 1.57 & .219 \\
DSM-IV Attention & $.48(.87)$ & $7.53(1.50)$ & 369.24 & .000 \\
DSM-IV Hyperactivity & $.64(.99)$ & $5.65(2.74)$ & 76.65 & .000 \\
DSM-IV Oppositional/Defiant & $.28(.68)$ & $3.18(2.53)$ & 29.92 & .000 \\
Connors Cognitive Problems/Inattention & $44.60(3.72)$ & $70.22(9.38)$ & 144.23 & .000 \\
Connors Hyperactivity & $46.56(3.94)$ & $73.35(12.01)$ & 106.98 & .000 \\
Connors ADHD Total & $44.68(4.03)$ & $73.71(6.67)$ & 309.74 & .000 \\
Connors Oppositionality & $44.04(5.14)$ & $60.12(13.62)$ & 29.04 & .000 \\
\hline
\end{tabular}


STIMULANT MEDICATION AND RECALL

Table 2

Means for the two diagnostic groups on relevant story recall variables

\begin{tabular}{|c|c|c|}
\hline Story Recall Variable & $\begin{array}{l}\text { Comparison }(n=25) \\
M(S E)\end{array}$ & $\begin{array}{l}\operatorname{ADHD}(n=17) \\
M(S E)\end{array}$ \\
\hline \multicolumn{3}{|l|}{ Growing Pains } \\
\hline \multicolumn{3}{|l|}{ Importance (\% recalled) } \\
\hline Low & $4.68(1.03)$ & $4.12(1.25)$ \\
\hline Medium & $6.16(.91)$ & $4.53(1.11)$ \\
\hline High & $15.48(1.32)$ & $12.18(1.60)$ \\
\hline \multicolumn{3}{|l|}{ Causal Chain Status (\% recalled) } \\
\hline Off Chain & $4.96(.89)$ & $3.82(1.08)$ \\
\hline On Chain & $15.12(1.43)$ & $11.59(1.73)$ \\
\hline Global Coherence (1-4 rating) & $2.20(.12)$ & $2.19(.28)$ \\
\hline \multicolumn{3}{|l|}{ Fables } \\
\hline \multicolumn{3}{|l|}{ Importance (\% recalled) } \\
\hline 1 Low & $29.07(3.13)$ & $23.58(3.80)$ \\
\hline 2 Low Medium & $38.29(3.24)$ & $42.02(3.92)$ \\
\hline 3 High Medium & $57.75(2.97)$ & $49.76(3.60)$ \\
\hline 4 High & $66.56(2.83)$ & $67.28(3.43)$ \\
\hline \multicolumn{3}{|l|}{ Causal Chain Status (\% recalled) } \\
\hline Off Chain & $28.38(3.08)$ & $27.17(3.73)$ \\
\hline On Chain & $54.72(2.60)$ & $50.57(3.15)$ \\
\hline Global Coherence (1-4 rating) & $2.36(.11)$ & $1.82(.21)$ \\
\hline
\end{tabular}

Note: Comparison group averaged across two sessions

ADHD group on placebo condition only 
STIMULANT MEDICATION AND RECALL

Table 3

Means for children with ADHD in the medication and placebo conditions

\begin{tabular}{|c|c|c|}
\hline \multirow[t]{2}{*}{ Story Recall Variable } & \multirow{2}{*}{$\begin{array}{l}\text { Medication }(n=17) \\
M(S E)\end{array}$} & \multirow{2}{*}{$\begin{array}{l}\text { Placebo }(n=17) \\
M(S E)\end{array}$} \\
\hline & & \\
\hline \multicolumn{3}{|l|}{ Growing Pains } \\
\hline \multicolumn{3}{|l|}{ Importance ( $\%$ recalled) } \\
\hline Low & $4.71(1.37)$ & $4.12(1.18)$ \\
\hline Medium & $6.24(1.24)$ & $4.53(.92)$ \\
\hline High & $15.47(2.06)$ & $12.18(1.72)$ \\
\hline \multicolumn{3}{|l|}{ Causal Chain Status (\% recalled) } \\
\hline Off Chain & $5.18(1.20)$ & $3.82(.93)$ \\
\hline On Chain & $14.35(1.93)$ & $11.59(1.60)$ \\
\hline Global Coherence (1-4 rating) & $2.19(.21)$ & $2.19(.28)$ \\
\hline \multicolumn{3}{|l|}{ Fables } \\
\hline \multicolumn{3}{|l|}{ Importance (\% recalled) } \\
\hline 1 & $28.43(5.46)$ & $23.58(4.74)$ \\
\hline 2 & $38.43(3.91)$ & $42.02(4.65)$ \\
\hline 3 & $57.67(4.42)$ & $49.76(4.60)$ \\
\hline 4 & $65.50(4.12)$ & $67.28(3.92)$ \\
\hline \multicolumn{3}{|l|}{ Causal Chain Status (\% recalled) } \\
\hline Off Chain & $38.10(5.43)$ & $27.17(4.04)$ \\
\hline On Chain & $50.82(3.70)$ & $50.57(3.89)$ \\
\hline Global Coherence (1-4 rating) & $2.05(.18)$ & $1.82(.21)$ \\
\hline
\end{tabular}

